\title{
APPLICATION OF PARTICLE PACKING THEORY IN ULTRA HIGH STRENGTH CONCRETE MIX DESIGNS AND EXPERIMENTAL ANALYSIS WITH SPECIAL REFERENCE TO SOME OF THE PROJECTS
}

\author{
Rahul Mathur ${ }^{1}$

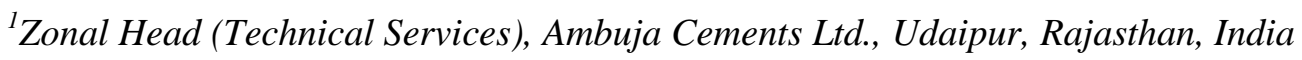

\begin{abstract}
Concrete has fast grown as an answer to almost all the construction needs of a society or a nation or global mass, whatever may be the scale. It has crossed a whole series phases where the Engineers in different ages have learned about its behavior under different conditions and the parameter those are responsible and controller of the same. With the passage of time, the experimental analysis enabled us to reach to the micro structure in depth and decipher some of the critical parameters like micro pores, particle size distribution, Transition zone and its significance and the "particle packing", which has enhanced understanding of the concept of Concrete Mix Design and enabled us to design High Strength High Performance Concrete.

The Article Deals with the concept of application of Particle packing theory Ultra High Strength Concrete Mix Design, where cement alone cannot contribute in the Compressive Strength of the Concrete by way of bond as the transition zone tend to fail much before arrival to the targeted strength and moreover, not all cement is often used in the hydration, owing to very low Water to Cement Ratio which may be of the order of 0.15 to 0.18 and many particles remained unhydrated or partially hydrated and they contribute in particle packing alone. The "particle packing" is the second parameter which is contributor in the strength of the concrete and is a function of the overall PSD, better is the PSD, better shall be packing and more will be the energy needed to break it. In this article the due consideration has been on using postulates of the particle packing and developing a mix design for UHSC. We shall also study the mix design of M100 grade concrete.
\end{abstract}

Keywords: Transition Zone, Particle Packing, Ultra High Strength Concrete (UHSC), and Concrete microstructure $* * *$

\section{INTRODUCTION}

The Concrete as a construction material empowers the technocrats and the clients for adopting or opting construction suitable to their needs and expectations. Concrete to us is not just intermixing of ingredients anymore but now is a material which can be tailored to the specific needs with a vast scope in $R \& D$.

With the rising population, shift of mass towards urbanization, up gradation of the habitats and so on are the factors which have shrunk the horizontal extents and thus need for exploring verticals is going higher day by day. This has put its due stress on the construction practices.

The class of High Performance Concrete (HPC) has emerged as a solution for constructions which need high strength and durability and there is one more class "Ultra High Strength Concrete (UHSC)" for even more stringent needs.

As defined by ACI, "HPC is defined as a concrete meeting special combination of performance and uniformity requirements that cannot always be achieved routinely using conventional constituents and normal mixing, placing, and curing practices". Characteristics that may be considered critical for particular application

$>$ Ease of placement

$>$ Compaction without segregation

$>$ Early age strength

$>$ Long-term strength and mechanical properties

$>$ Permeability

$>$ Density

$>$ Heat of hydration

$>$ Toughness

$>$ Volume stability

$>$ Long life in severe environments

Note: according to the ACI definition, durability under severe environmental conditions is an optional, not a mandatory requirement for $\mathrm{HPC}$.

"Ultra High Performance Concrete" is nothing but the upper version of the above.

\section{THE CONCEPT OF PARTICLE PACKING}

The packing of aggregate particles in a concrete mass is the degree to which the particles are measured in terms of packing density which is [1] nothing but the ratio of volume of solids to the volume of voids. 
In a better sense, particle packing is the physics of rearrangement of particles according to their size and shape by way of interlocking and reorientation of each one of them accordingly so that each particle acts as a wedge to its adjacent at the point of external stress applied. Better is the particle packing, lesser shall be volume of voids and thus higher will be density. This therefore give its due advantage in the compressive strength of the concrete as initial energy is being consumed by a good particle packing alone before stresses are set into the bond of cement paste and the aggregate surface

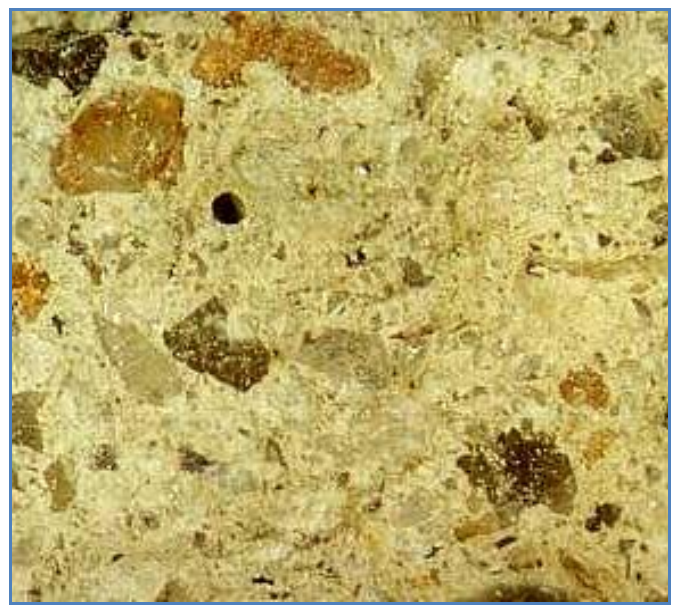

\subsection{Concrete Microstructure and the Particle}

\section{Packing}

The microstructure of the concrete is nothing but the matrix of particles up to $75 \mu$ (Aggregate Powder) [2], 4.75mm to $75 \mu$ (Fine Aggregates) and greater than $4.75 \mathrm{~mm}$ (Coarse Aggregates) and as particle packing gets better, there are less voids available to be filled by cement paste and therefore this proves to be a better analogy to make concrete cost effective by enhancing the particle packing. It therefore results in a sustainable concrete too.

The effect of particle packing on the behavior of the concrete can be understood as that, to provide dimensional stability ${ }^{[2]}$ to the concrete mass it is desirable to reduce cement paste by substituting some of the cement by supplementary Cementitious Materials so that heat of hydration is reduced and therefore expansion or contraction at early age and Drying Shrinkage at later age are also reduced, but instead the packing can be improved by carefully selecting the particles and thereby reducing cement which gives dual advantage of volumetric stability in concrete at a lower cost.

\subsection{Concrete Mix proportioning and application of}

\section{Particle Packing Theory}

There are various methods of Concrete Mix Proportioning prevalent worldwide some of them are like DOE which has considered Water Cement Ratio with the compressive strength and is practically an advanced method, this method was revised in the year 1988, ACI method is another method which is one of the most popular in which relationship between W/C ratio and Compressive strength is assumed to be unique and the IS: 10262 - 2009 has considered many of the criteria from ACI.

Particle packing model may be classified as

- Discrete Model

- Continuous Model

Discrete Model is further classified as Binary, Ternary and Multimodal Mixture Model ${ }^{[1]}$. The fundamental assumption of the discrete approach is that each class of particle will pack to its maximum density in the volume available. The discrete model is classified as (i) binary (ii) Ternary and (iii) Multimodal mixture model. [1]

\subsubsection{The Binary Model}

Basic theory of particle packing was started by Furnas, he assumed particles as spheres and assumed that small particles fill well in the space between bigger particles and that the mixture was particles of two sizes. If in the composition volume of fraction of fine is higher than Coarse, it is called as "fine grain dominant" and opposite to it is called as "Coarse grain dominant."

This is possible only when particle diameter of fine grain are much less than that of coarse grain and if this does not remain as a case then packing of the binary mixture will depend upon the ratio of diameter of fine grain to that of coarse grain.

\subsubsection{The Ternary Mixture Model}

The model of Toufar ${ }^{[1]}$ states that small particles with diameter ratio $d_{1} / d_{2}>0.22$ will not be small enough to situate in the spaces in coarse aggregates and therefore in the packing of the matrix shall be three cases may arise

$$
\begin{aligned}
& \text { I. When in packed area coarse particle are dominant } \\
& \text { II. When in the packed area there are lager particles } \\
& \text { III. When in the packed area fine particles are } \\
& \text { dominant }
\end{aligned}
$$

For a multi-component system, it is assumed that any two Components form binary mixtures. Then the packing density for the total multi-component mixture is calculated by summation of the contribution from all the binary mixtures. [1]

\subsubsection{The Multi Component Mixture Model}

For a given mixture, the packing density is expressed as a function of the fractional solid volume of each grain size present

\subsection{The Continuous Model}

Continuous approach assumes that all possible sizes are present in the particle distribution system, that is, discrete approach having adjacent size class's ratios that approach 1:1 and no gaps exist between size classes. [1] 
The fundamental work of Féret, Fuller showed that the packing of concrete aggregates is affecting the properties of the produced concrete. Both Féret as well as Fuller and Thomsen concluded that the continuous grading of the composed concrete mixture can help to improve the concrete properties. Féret demonstrated that the maximum strength is attained when the porosity of the granular structure is minimal.

\section{OUR STUDY ON THE UHPC SELF COMPACTING CONCRETE}

Our team undertook a study at our Dadri unit Concrete Lab. M100 grade of concrete using the locally available materials was the basis and accordingly on basis of the properties of Cement, Aggregates and the Admixtures a mix design was prepared and a series of trials were carried out.

\subsection{Scope}

The scope of study was following:

1. Can UHSCC be achieved using locally available materials?

2. What is the effect of fines and microfines on the Fresh and Hardened State Concrete?

3. What are the various combinations possible of admixtures, Fines and Microfines and their dosage?

4. What are the effects of different microfines on the Concrete mass?

What are the optimum $\mathrm{W} / \mathrm{C}$ ratio and the optimization of the structure of mix design?

\section{2: Methodology}

Keeping above points into consideration, a mix design accordingly was prepared with the assumption that water available for the hydration will be limited and the same water in the fresh state shall also contribute into the workability and other rheological properties. The first objective was to set the mix design to achieve 100MPa strength and then adopt the optimization/restructuring cycle. To second and third point a/a the combined gradation curve of the Concrete Mix was prepared and optimized and a balancing between fines and microfines was set. The cement used was Ambuja Cement which was PPC, the source of coarse aggregates was Haridwar, and Admixture was Polycarboxylic (PC) based with Viscosity Modifying Agent (VMA). In different trials two microfines viz. GGBS (Alccofine 1203), Silica fume and their combination were studied in the first cycle.

Six different set of trials were conducted as per following combinations:

1. A base design having no microfine but only admixture and VMA

2. Mix design having $100 \%$ Alccofine 1203

3. Mix Design with $100 \%$ Silicafume

4. Mix Design with $70 \%$ Alccofine 1203 and 30\% Silicafume
5. Mix Design with $60 \%$ Alccofine 1203 and $40 \%$ Silicafume

6. Mix Design with 50\% Alccofine 1203 and 50\% Silicafume

While mobilizing the binding character of Cement and pozzolana the density of the mass was also to be duly enhanced to ensure better packing

\subsection{The Concrete Mix Design}

The concrete mix design was done for being UHPC of Self Compacting Concrete with two hours workability retention with initial flow on flow table of $700 \mathrm{~mm}$ and "V" funnel flow in 5Secs and collapse slump after 2 hours. The W/C ratio was kept at 0.24 with $12 \%$ Micro fines and $1.56 \%$ PC and $0.36 \%$ of VMA.

The first objective was to set a benchmark of $100 \mathrm{MPa}$ achievement with the mix design to enable us to optimize for enhancement of the strength. The second objective in the line was to achieve the target mean strength, for this case it was kept at $112 \mathrm{MPa}$.

\begin{tabular}{|l|l|}
\hline A/C Ratio & 2.453 \\
\hline W/C Ratio & 0.255 \\
\hline S/A Ratio & 0.380 \\
\hline$\%$ Alccofine Content & $12 \%$ \\
\hline \% Admixture Dosage & $1.56 \%$ \\
\hline \% VMA Dosage & $0.36 \%$ \\
\hline
\end{tabular}

\begin{tabular}{|l|l|}
\hline $20 \mathrm{~mm}$ passing & $100 \%$ \\
\hline $600 \mu$ passing & $50 \%$ \\
\hline Cement Type & PPC Dadri Unit \\
\hline Coarse Aggregates & Crushed \\
\hline Fine Aggregates & River \\
\hline
\end{tabular}

\subsection{Results obtained (Cycle 1)}

In all the trials, the objectives related with the fresh state were achieved on flow table, "V" funnel and "U" tube flow tests as per EFNARC guidelines (Please refer table 1)
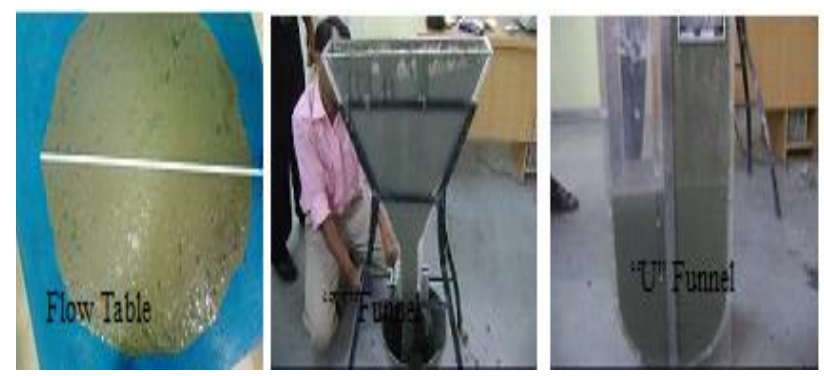
Table 1:- Workability in I Trials Cycle

\begin{tabular}{|c|c|c|c|c|c|c|c|}
\hline \multirow{3}{*}{\begin{tabular}{|l|} 
Trial \\
No.
\end{tabular}} & \multirow{3}{*}{$\begin{array}{l}\text { Grade of } \\
\text { concrete }\end{array}$} & \multirow[t]{3}{*}{ Trial Type } & \multirow{3}{*}{$\begin{array}{l}\text { Trial with } \\
\text { Admixture }\end{array}$} & \multicolumn{4}{|c|}{ SCC Parameters } \\
\hline & & & & \multicolumn{2}{|c|}{ Slump Fow } & \multirow{2}{*}{$\begin{array}{l}\mathrm{V} \\
\text { Funne1 } \\
\text { Fow }\end{array}$} & \multirow{2}{*}{$\begin{array}{l}\text { "U" } \\
\text { Tube } \\
\text { flow }\end{array}$} \\
\hline & & & & T50 & Final & & \\
\hline 1 & M100 & Bass & $\overline{\mathrm{PC}}$ & $10 \mathrm{Sec}$ & $600 \mathrm{~mm}$ & $20 \mathrm{Sec}$ & $\mathrm{H1}$ ? H2 \\
\hline 2 & M100 & $100 \%$ Alcc ofine & $\overline{\mathrm{PC}}$ & $6 \mathrm{Sec}$ & $730 \mathrm{~mm}$ & $9 \mathrm{Sec}$ & $\mathrm{Hl}=\mathrm{H} 2$ \\
\hline 3 & M100 & $100 \%$ Alcc ofine & $\overline{\mathrm{PC}}$ & $6 \mathrm{Sec}$ & $730 \mathrm{~mm}$ & $8 \mathrm{Sec}$ & $\mathrm{Hl}=\mathrm{H} 2$ \\
\hline 4 & M100 & $100 \%$ Alcc ofine & $\overline{P C}$ & $5 \mathrm{Sec}$ & $740 \mathrm{~mm}$ & $8 \mathrm{Sec}$ & $\mathrm{Hl}=\mathrm{H} 2$ \\
\hline 5 & M100 & $\begin{array}{l}70 \% \text { Alkcofine } 30 \% \\
\text { MS }\end{array}$ & $\overline{\mathrm{PC}}$ & $6 \mathrm{Sec}$ & $700 \mathrm{~mm}$ & $8 \mathrm{Sec}$ & $\mathrm{Hl}=\mathrm{H} 2$ \\
\hline 6 & M100 & $\begin{array}{l}\text { 60\%Alkcofine } 40 \% \\
\text { MS }\end{array}$ & $\overline{P C}$ & $7 \mathrm{Sec}$ & $700 \mathrm{~mm}$ & $9 \mathrm{Sec}$ & $\mathrm{Hl}=\mathrm{H} 2$ \\
\hline 7 & M100 & $\begin{array}{l}50 \% \text { Alcc ofine } 50 \% \\
\text { MS }\end{array}$ & $\overline{P C}$ & $7 \mathrm{Sec}$ & $680 \mathrm{~mm}$ & $9 \mathrm{Sec}$ & $\mathrm{Hl}=\mathrm{H} 2$ \\
\hline 8 & M100 & $100 \%$ Silicafume & $\overline{\mathrm{PC}}$ & $8 \mathrm{Sec}$ & $650 \mathrm{~mm}$ & $10 \mathrm{Sec}$ & $\mathrm{Hl}$ ?H2 \\
\hline
\end{tabular}

At the same time in the cycle as evident from results in the table 2 as under, it was only $100 \%$ Alccofine 1203 dosage which could attain magical strength figure of even $100 \mathrm{MPa}$.

Table 2:- Strength achieved in I Trials Cycle

\begin{tabular}{|c|c|c|c|c|c|c|}
\hline \multirow[t]{2}{*}{ Trial No. } & \multirow{2}{*}{\begin{tabular}{|l|} 
Grade of \\
concrete
\end{tabular}} & \multirow[t]{2}{*}{ Trial No. } & \multicolumn{3}{|c|}{ Strength (Mpa) } & \multirow{2}{*}{\begin{tabular}{|l|} 
Average \\
Weight of \\
Cube
\end{tabular}} \\
\hline & & & $3 \mathrm{Da}$ & 7 Day & 28 Day & \\
\hline 1 & M100 & Base & 45.5 & 59.85 & 80.23 & 8.16 \\
\hline 2 & M100 & $100 \%$ Alccofine & 52.8 & 73.80 & 99.00 & 8.30 \\
\hline 3 & M100 & 100\% Alccofine & 49.20 & 74.40 & 99.00 & 8.28 \\
\hline 4 & M100 & 100\% Alccofine & 58.50 & 81.50 & 101.00 & 8.30 \\
\hline 5 & M100 & 70\%AAlccofine 30\% MS & 51.75 & 70.85 & 90.10 & 8.25 \\
\hline 6 & M100 & 60\%Alccofine 40\% MS & 45.90 & 63.22 & 85.60 & 8.23 \\
\hline 7 & M100 & $50 \%$ Alccofine $50 \%$ MS & 45.00 & 60.08 & 82.35 & 8.18 \\
\hline 8 & M100 & 100\% Slicafume & 38.25 & 53.25 & 84.15 & 8.19 \\
\hline
\end{tabular}

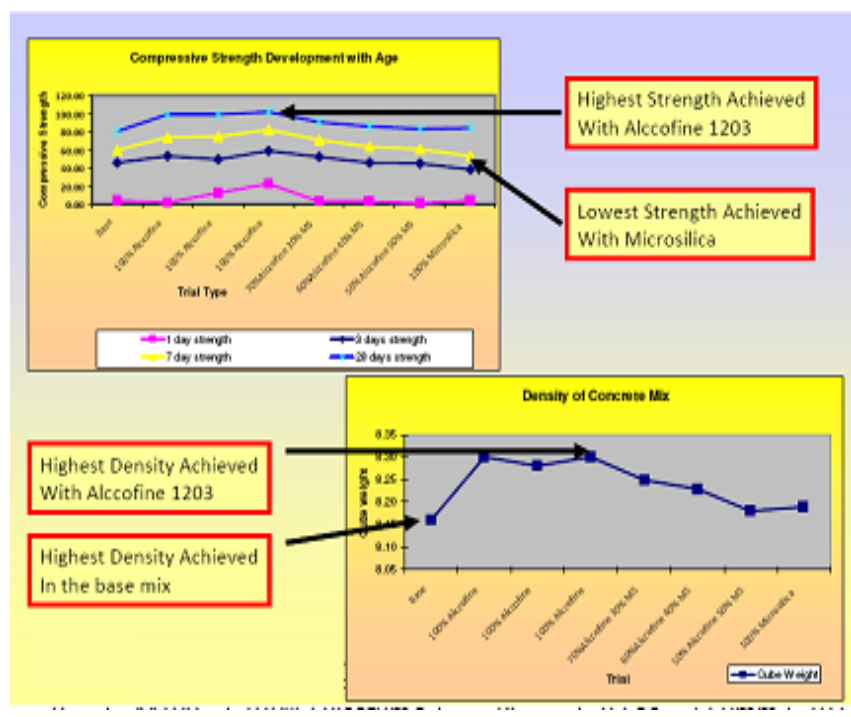

\section{4: Batch Optimization and Results Obtained}

\section{(Cycle 2)}

In the cycle II of the trials, the design parameters were kept constant but following structural changes in the composition were made:

A. W/C ratio lowered to 0.23
B. Coarse Aggregate $16 \mathrm{~mm}$ (CAI) down size were lowered to $24.6 \%$

C. Fine aggregate were increased by $3 \%$ to improve the PSD

D. Admixture dosage was kept the same

E. Microfine (Since Alccofine 1203 qualified in trial I so it was employed in optimization cycle) dosage was kept the same.

There were following changes observed on the fresh and hardened Concrete

a. The slump was collapse after 2 hours

b. Initial flow was $730 \mathrm{~mm}$

c. The average of three cube strength with the age increased vis $-\mathrm{a}-$ vis that in Cycle No. 1 were as under

I. 3days strength $=\quad 75.24 \mathrm{MPa}(58.50 \mathrm{MPa}$ in Cycle 1)

II. 7days strength $=92.67 \mathrm{MPa}(81.50 \mathrm{MPa}$ in Cycle 1)

III. 28days strength $=\quad 115.27 \mathrm{MPa}(101 \mathrm{MPa}$ in Cycle 1)

\begin{tabular}{|c|c|c|c||}
\hline \multicolumn{5}{|c|}{ SL No } & Weight & velocity & Time \\
\hline 1 & 8.300 & $4.590 \mathrm{~m} / \mathrm{s}$ & $32.70 \mu$ Secs \\
\hline 2 & 8.280 & $4.560 \mathrm{~m} / \mathrm{s}$ & $32.90 \mu$ Secs \\
\hline 3 & 8.300 & $4.410 \mathrm{~m} / \mathrm{s}$ & $34.00 \mu$ Secs \\
\hline \multicolumn{5}{|c||}{} \\
\hline SL No & Weight & velocity & Time \\
\hline 1 & 8.300 & $4.500 \mathrm{~m} / \mathrm{s}$ & $34.90 \mu$ Secs \\
\hline 2 & 8.310 & $4.450 \mathrm{~m} / \mathrm{s}$ & $34.50 \mu$ Secs \\
\hline 3 & 8.280 & $4.350 \mathrm{~m} / \mathrm{s}$ & $34.50 \mu$ Secs \\
\hline
\end{tabular}

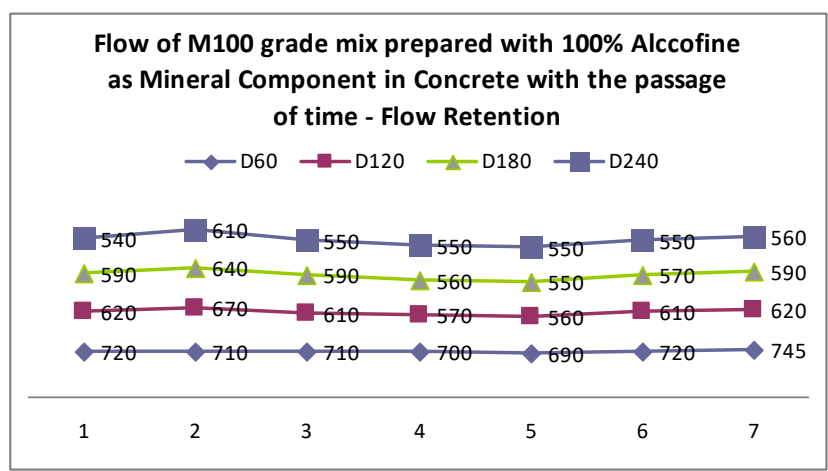

Therefore It Could Be Said That In This Optimization Cycle Even M100 Grade Was Achieved.

1. High density of the mix was achieved and subsequently higher packing

2. Cube failure pattern was dumb bell showing aggregate crushing dominantly 


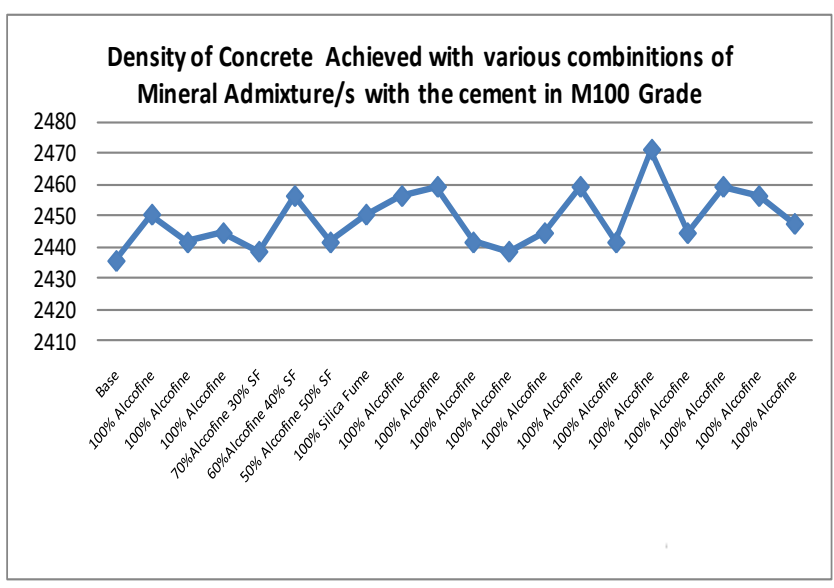

3. The trial has established compatibility of PPC and Alccofine to act simultaneously in the mix.

4. Alccofine was used as cement substitute and since fly ash was already present in PPC, no further addition was possible and hence not done.

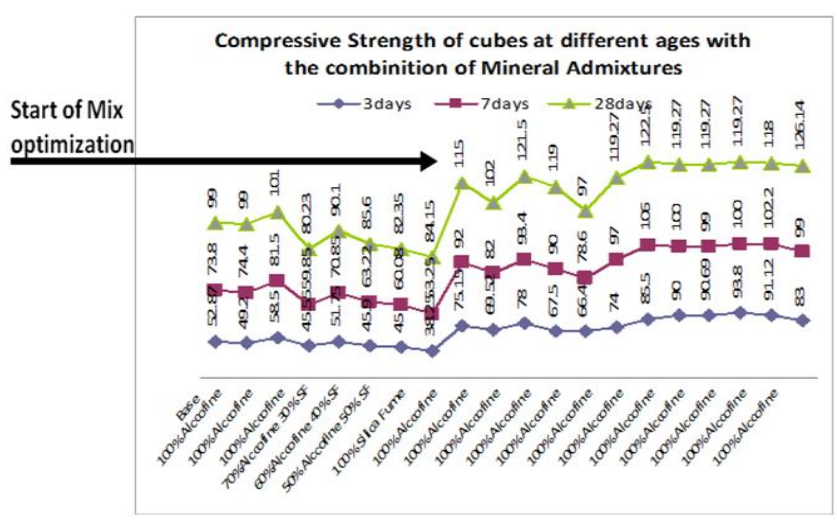

5. The trial was made with the locally available materials and so their capability in a concrete mix was also established.

\section{CONCLUSION}

The need for High Performance or High Strength Concrete is increasing day by day and there is no direct formula available which may give the desired design, as matters of facts, most of the codes world over, even have no parameters for concretes of grades like M80 and above. At the same time it's also not good to employ extra quantity of cement or SCM or their combinations. A proper understanding of the particle packing and the way to achieve it may resolve the problem and a suitable mix design may be evolved.

In our case of study of UHSC of M100, the application of particle packing concept and achieving the best gradation curve of mixture proved useful in achieving optimum composition and by process of applying correction after successive trials we could reach to very high strength of $126 \mathrm{MPa}$ in a trial and average of all the trials as $115 \mathrm{MPa}$. There was a visible shift from strength level of $85 \mathrm{Mpa}$ to $115 \mathrm{MPa}$, after a work on particle packing was duly done.
Particle packing concept is not a recent concept but its understanding was already there in the beginning of $20^{\text {th }}$ Century and with the time has gained its due importance in application in Concrete Mix design with performance

\section{ACKNOWLEDGEMENT}

The Author expresses his since gratitude to all the references which helped to provide adequate reference material to make this article in its shape. Sincere thank is also to my seniors, Mr. Yogesh D. Barot and Mr. Sanjeev Sharma for valuable inputs and guidance. My thanks to all my laboratory colleagues for excellent work in laboratory towards trials on the mix design with precision.

\section{REFERENCES}

[1] Review of Particle Packing Theories Used For Concrete Mix Proportioning, Mangulkar M. N., Dr. Jamkar S.S., International Journal Of Scientific \& Engineering Research, Volume 4, Issue 5, May-2013

[2] Applying Theories of Particle Packing and Rheology to Concrete for Sustainable Development, Vivian Wong Department of Civil Engineering, The University of Hong Kong, Hong Kong, China faiyin@ hku.hk, Ka Wai Chan Department of Civil Engineering, The University of Hong Kong, Hong Kong, China kwchan84@hku.hk, Albert Kwok Hung Kwan Department of Civil Engineering, The University of Hong Kong, Hong Kong, China khkwan@hku.hk

[3] PACKING CALCULATIONS APPLIED FOR CONCRETE MIX DESIGN, M. Glavind, E. J. Pedersen, Danish Technological Institute, Denmark, Proceedings Creating with Concrete, May 1999, University of Dundee

[4] Properties of Concrete (Fourth Edition) by A.M.Neville, Pearson Education

[5] Concrete Technology by A.M.Neville \& J.J.Brooks, Pearson Education

[6] ACI Recommendations

[7] Brochures on Alccofine 1203

[8] Various literatures printed by Ambuja Cements Ltd. On Concrete Technology.

[9] EFNARC Guidelines

[10] NAN SU Method of SCC Mix Design

\section{BIOGRAPHY}

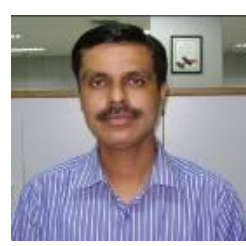

The author, Mr. Rahul Mathur finished his Bachelor Degree from University of Rajasthan in 1994 and possesses more than 22 years of experience in various capacities which includes Projects, Academics and Technical Services. For past 16 years he is working with Ambuja Cements Ltd. And at presents holds the post of Zonal Head in Technical Services. 